\title{
Juan Carlos Moretti (1941-2008): Testigo y actor de su tiempo
}

En 1998 en una de nuestras visitas periódicas al Cono Sur nos detuvimos en Montevideo, por razones de amistades, añoranzas de nuestro primer encuentro formal y el disfrute de ese reconocido teatro de la Banda Oriental. En agosto asistimos a la representación de la obra sobre Delmira Agustini La pecadora, habanera para piano de Adriana Genta, dirigida por Juan Carlos Moretti. Posteriormente en octubre Moretti pondría en escena de Raquel Diana Cuentos de hadas con el cual la autora y el director recibieron el codiciado Florencio (LATR Otoño 1999). Tuve el placer de conversar con "un hombre asequible y amable, dispuesto a compartir ideas," como lo registré en la entrevista publicada en LATR (Primavera 1999). Por mail de Gerardo Begérez, componente de El Galpón en Montevideo, supe del fallecimiento de Juan Carlos el miércoles 17 de octubre en su país natal.

En 1959 era estudiante de medicina, cuando se impuso de la creación de estudios teatrales en la mítica entidad montevideana. Así lo manifestó en nuestra conversación:

Di la prueba de admisión y estudié por cuatro años y hasta el día de hoy continúo en El Galpón. Empecé como actor y me interesó sobremanera la parte técnica, la de iluminación. Además en el teatro pasa un fenómeno por lo menos en nuestra tierra, que la gente se tiene que ocupar de todo, tenemos que ser multidisciplinarios. Yo siento que eso provoca un desarrollo a nivel de la imaginación, debido a los pocos medios conque se cuenta, obliga que aquella idea que uno quiere plasmar, debes encajarla con los pocos medios que uno tiene a su alcance.

El paso a director se produjo por su constante permanencia con los espectáculos, pues al estar a cargo del montaje de luz, estaba presente durante los meses que se presentaba una obra. El contacto diario y el aprendizaje con sus compañeros en el escenario, lo llevó a probar en dirección. En dicha entrevista reconoció que tuvo la oportunidad en 1993 de dirigir una pieza sobre otra personalidad del 1900, Juana de Ibarbourou, la otra Juana de 
Ariel Mastandrea. Obtuvo el Florencio como director, Ariel como autor y Anael Bazterrica como mejor actriz.

Con sencillas palabras nos entregó su prolongada trayectoria como director de escena, la que fuera coronada con diversos reconocimientos. En 2000 obtuvo el Premio Morosoli de Plata por su aporte cultural al país, otorgado por la Fundación Lolita Rubial. En el Festival de Cádiz del mismo año estableció contacto con el grupo Azar Teatro. Fue en el 2001 que Moretti viajó a España y se radicó en Valladolid donde trabajó con esa compañía. Dirigió los espectáculos Ñaque o de piojos y actores de Sanchis Sinisterra, El cruce sobre el Niágara la obra clásica de Alonso Alegría, y Delirios de mujer. Protagonizó La última noche de Giordano Bruno del italiano Renzo Sicco (por esta última Moretti fue galardonado por su actuación en el certamen Arcipreste de Hita en Guadalajara) y en Las apariencias engañan de Thomas Bernhard desempeñó el papel de Minetti. Tras siete años de ausencia regresó a Uruguay en 2007.

Tal vez las palabras de Gerardo Begérez en su mail, nos dejen un retrato hablado de Juan Carlos:

El Juanca para algunos, el Morettito para mí. Actor y director de largo recorrido artístico, aquí y en España. Formado en el Teatro el Galpón y miembro de su elenco casi una vida. Fue un luchador acérrimo del teatro independiente. Ayudó a construir la propia sala de El Galpón, cuando el teatro se construía con las manos de los artistas. Compañero de generación de Myriam Gleijer y de Luis Fourcade. Fue secretario General de El Galpón. Hombre ecuánime, afectuoso y justo, con un sentido del arte y del teatro que rozaban el amor profundo. Cosechó el cariño y el respeto de todos sus compañeros. Un referente para nuestra generación joven. Gran iluminador, técnico, actor y director. Un hombre de teatro. Innovador en el arte y en su vida. Fiel a sus principios éticos que lo forjaron como un ser humano inconmensurable, de esos que nunca deberían dejar de existir. Fue feliz hasta el último día. Siempre con su sonrisa refulgente que nos iluminaba a todos (...) Llevó su arte a todos los rincones de Europa, lugar que amaba y que planeaba volver este mes. Siguen partiendo los Maestros, los que construyeron los cimientos del arte teatral de este país. Y esto duele tanto. Pero yo sonrío al imaginarme su risa estridente y sus palabras oportunas.

Justo y sentido homenaje de un compañero de ruta, a un recordado y distinguido teatrista de nuestra América Latina.

Pedro Bravo-Elizondo

Wichita State University 